\title{
MASTITIS, RETAINED PLACENTA AND BCS EFFECT AND ON THE REPRODUCTIVE PERFORMANCES OF MONTBÉLIARDE DAIRY COWS RAISED IN THE AIN DEFLA REGION OF ALGERIA
}

\author{
Mekheldi Khira $^{1}$, Meliani Samia ${ }^{1 *}$, Zidane Khaled ${ }^{2}$ \\ ${ }^{1 *}$ Faculty of nature and life sciences, University of Tiaret, Algeria; \\ ${ }^{2}$ The veterinary sciences institute, University of Tiaret, Algeria; \\ "Corresponding Author Meliani Samia, e-mail: meianisamia@hotmail.com;
}

Received May 2020; Accepted June 2020; Published July 2020;

DOI: https://doi.org/10.31407/ijees10.313

\begin{abstract}
To evaluate the factors that may interfere with dairy cow's reproductive performances, this study was carried at a dairy farm at the Ain Defla region at the Algerian center. The cows used in the study were all from Montbéliardee breed. All cow's data were noted, feeding, reproduction, health status and score body. The placental retention, mastitis and postpartum metritis and the BCS at calving and at the first insemination were noted and the influence on the reproductive performance of Montbéliardee dairy cows were quantified. Cows having metritis had a calving to first service interval (CFSI) higher than other cows with 85,10 days and the longest open days or calving to conception interval (CCI) with 185days was recorded for cows with placental retention. In this study the best first service conception rate (FSCR) with 35\% was recorded in cows with a body condition score (BCS) between 3,5 and 4 at calving and the best CFSI of 121 days was recorded in cows with BCS between 2,5 and 3 at calving. This study showed the influence of peripartum pathologies on the success of artificial insemination and the open day's length.
\end{abstract}

Keywords: Score body, Postpartum calving- ${ }^{\text {st }}$ Artificial insemination interval. 